\title{
Mutation analysis in 57 unrelated patients with MPS II (Hunter's disease)
}

\author{
E Vafiadaki, A Cooper, L E Heptinstall, C E Hatton, M Thornley, J E Wraith
}

\begin{abstract}
Genomic DNA from 57 unrelated MPS II (Hunter's disease) patients was analysed for mutations of the iduronate sulphatase (IDS) gene. The aim of the study was threefold: to identify the primary genetic lesion in patients, to investigate the correlation between genotype and phenotype, and most importantly, to provide reliable carrier testing for female members once the family mutation was identified. In 42 patients, point mutations were identified involving single base substitutions, deletions, or insertions. These included four new nonsense mutations (R8X, C84X, E245X, Y466X), six new missense mutations (D45N, N115Y, P228L, P266R, E434K, I485K, W502C), three new insertions (c70C71ins, c652C654ins, c709G710ins), six new deletions (c500delC, c705delC, c1023delA, c1049delA, c1141delC, c1576delG), and five new mutations involving splice sites (IVS1-2 a $\rightarrow$ g, IVS2-10 $\quad t \rightarrow g, \quad$ IVS5 + $2 \quad t \rightarrow g \quad$ L236L, IVS $7+2 t \rightarrow c)$. One patient had a new seven base deletion in exon 9 (c1482$1488 \mathrm{del})$. Four patients were shown to have complete deletions of the IDS gene and two deletions involved one or more exons. Previously described mutations present in these patients were Q80X, P86L, R172X, G374G, S333L, R443X, and R468Q. In eight patients, no mutation was detected throughout the entire coding region. Most mutations that result in MPS II appear to be unique. Absence of the probands' mutations in eight of nine maternal grandmothers suggests many mutations have arisen recently. Prediction of the clinical phenotype from the identified genotype was difficult in some families, and further studies using reverse transcription polymerase chain reaction are needed to confirm the predicted effects on the IDS mRNA suggested by genomic analysis.
\end{abstract}

Willink Biochemical Genetics Unit, Royal Manchester Children's Hospital, Pendlebury, Manchester M27 4HA, UK

E Vafiadaki

A Cooper

L E Heptinstall

C E Hatton

M Thornley

J E Wraith

Correspondence to: Dr Cooper.

email: alan@willink. demon.co.uk

Accepted 12 March 1998 tion of these compounds in various tissues and leads to progressive derangement of function. Clinical presentation shows a spectrum of mild to severe forms as a result of different mutations in the functional gene. ${ }^{3}$ These mutations comprise missense and nonsense mutations, mutations affecting splicing, small insertions and deletions, partial gene deletions, and deletions or rearrangements of the whole IDS gene. ${ }^{3}{ }^{4}$ The severe phenotype is characterised by facial dysmorphism, short stature, hepatosplenomegaly, bone abnormalities, heart valve disease, mental retardation, and death in the second decade. ${ }^{1}$ The mildest forms show no central nervous system involvement and prolonged survival.

\section{Methods and materials}

Of the 57 patients in this study, most attended the Willink Unit for assessment and follow up. A smaller group was diagnosed from samples received from overseas, and clinical details were obtained from the referring clinician. For the purposes of this report, the designation "severe" indicates the classic MPS II phenotype, including early diagnosis, short stature, coarse facial appearance, hepatosplenomegaly, skeletal disease, and progressive neurodegeneration. These patients normally die in their mid-teens. "Mild" patients are those with normal intellectual functions who have survived well into adult life. Patients classified as "intermediate" usually have mild or moderate learning difficulties and less severe skeletal disease. These patients often survive until their late teens or early 20s. Death in this group is usually caused by cardiorespiratory disease.

Initial diagnosis was by assay of iduronate-2sulphatase in plasma using a tritiated disaccharide substrate. ${ }^{2}$ DNA was isolated from white blood cell pellets by boiling. Pellets were resuspended in $50 \mathrm{mM} \mathrm{NaOH}$ and placed in a boiling water bath for 15 minutes. Samples were then neutralised with $1 \mathrm{M}$ Tris $\mathrm{HCl}, \mathrm{pH} 7.5$, and centrifuged at $10000 \times g$ for five minutes. The supernatants were used for subsequent analysis. IDS exons and flanking intronic regions were amplified by the polymerase chain reaction (PCR) using $100 \mu \mathrm{M}$ dNTPs, $1 \times$ Taq buffer, 0.2 U Super Taq (HT Biotechnology, Cambridge, UK), 40 pmol primers, and 2-5 $\mu \mathrm{l}$ template in a final volume of $50 \mu \mathrm{l}$. Temperature cycling (30-35 cycles) was performed on an Omnigene thermal cycler (Hybaid, Middlesex, UK) using the primers and annealing temperatures shown in table 1 . When required, exon 3 was amplified using nested primer pairs, IIIb-5' and IIIb-3' followed by IIIa-5' and IIIa3'. This extra step prevented amplification of the pseudogene sequence. The large exon nine was amplified in three overlapping fragments. PCR products were purified using QIAquick 
Table 1 Primers and annealing temperatures used during temperature cycling

\begin{tabular}{|c|c|c|c|}
\hline Exon & Primer sequence & $\begin{array}{l}\text { Annealing } \\
\text { temperature }\end{array}$ & $\begin{array}{l}\text { Product } \\
\text { (base pairs) }\end{array}$ \\
\hline$\overline{\mathrm{I}-5}$ & 5' CCA CCT GCT GCA GCC TGT CC 3' & & \\
\hline I-3' & 5' AGA TGG CAG GGA GGG CGT GG 3' & $65^{\circ} \mathrm{C}$ & 183 \\
\hline II-5' & 5' AGG GTT CAG TGT CAG TGC 3' & & \\
\hline II-3' & 5' AAC CCT CAG TGC ACG AAG 3' & $61^{\circ} \mathrm{C}$ & 244 \\
\hline IIIa-5' & 5' GAT GGC AGA CAT GTT TTG 3' & & \\
\hline IIIa-3' & 5' GCT GGA TTC AGA CAC CAC 3' & $58^{\circ} \mathrm{C}$ & 289 \\
\hline IIIb-5' & 5' GAG GGT TCA GTG TCA GTG CAG G 3' & & \\
\hline IIIb-3' & 5' TCA GAC ACC ACA AAC CAA GAG 3' & $55^{\circ} \mathrm{C}$ & 1074 \\
\hline IV-5' & 5' GTG GGG TGT TGA AAG ATC & & \\
\hline IV-3' & 5' TGG TAT ATA ACC AGT TCA CAG 3' & $58^{\circ} \mathrm{C}$ & 242 \\
\hline V-5' & 5' TTC TTG CAC TAA AAA AGG TGA T 3' & & \\
\hline V-3' & 5' TGT CAC AGC TGA TGC TGG AT 3' & $58^{\circ} \mathrm{C}$ & 286 \\
\hline VI-5' & 5' TTG TGC TTT TGC TAA AAG 3' & & \\
\hline VI-3' & 5' ACG ACA CTA TGT CAT CAG 3' & $55^{\circ} \mathrm{C}$ & 276 \\
\hline VII-5' & 5' CTT GGC AAT TTA AAT TGC 3' & & \\
\hline VII-3' & 5' TTT CAC AGG AAA GTT CAG 3' & $61^{\circ} \mathrm{C}$ & 243 \\
\hline VIII-5' & 5' GTG GTA TGA TGA TTA TTC 3' & & \\
\hline VIII-3' & 5' AAC TAA AGG TGA TCT TAC 3' & $55^{\circ} \mathrm{C}$ & 275 \\
\hline IXa-5' & 5' TGG CAG GCT TTT ATA ATG 3' & & \\
\hline IXa-3' & 5' AGG TAC GGA TCC ТCT TCC 3' & $55^{\circ} \mathrm{C}$ & 230 \\
\hline IXb-5' & 5' GAG CTG TGC AGA GAA GGC 3' & & \\
\hline IXb-3' & 5' TGA AGC CAA CCC ACA CAG 3' & $61^{\circ} \mathrm{C}$ & 229 \\
\hline IXc-5' & 5' GAT ATA AAG ATC ATG GGC 3' & & \\
\hline IXc-3' & 5' TCT CAC CAG CTG GAA GGG 3' & $55^{\circ} \mathrm{C}$ & 262 \\
\hline
\end{tabular}

PCR purification kits (Qiagen Ltd, West Sussex, UK), according to the manufacturer's instructions. Manual cycle sequencing was performed using the Circumvent DNA kit and the Phototope detection kit (New England Biolabs, Herts, UK), according to the manufacturer's instructions. Automated fluorescent dye terminator cycle sequencing was performed using $\mathrm{ABI}$ prism dye terminator cycle sequencing ready reaction kits containing Amplitaq DNA polymerase, FS (Perkin Elmer) and analysed on an ABI Prism 377 DNA sequencer. Resultant sequences were imported into Sequence Navigator (Perkin Elmer) for alignment, editing, and mutation analysis. Restriction digestion studies were performed with appropriate enzymes using the buffer and conditions recommended by the manufacturer.

\section{Results and discussion}

Mutations detected in genomic DNA from the 57 unrelated patients included four complete gene deletions or rearrangements and two partial deletions involving at least one exon. Nine patients had nonsense mutations, 18 had missense mutations, six had single base deletions, three had single base insertions, six had mutations affecting splicing, and one had seven base deletions (table 2). Twenty five new mutations involving single base substitutions or small deletions or insertions were identified.

Four patients had new nonsense mutations that resulted in the expected severe phenotype (C84X (two unrelated patients), E245X, and Y466X). The C84X mutation appears to have arisen independently in the two unrelated patients, rather than having been inherited from a common ancestor, because the mutation was not detected in the one maternal grandmother investigated. Surprisingly, a fifth patient with the R8X mutation was only mildly affected, suggesting that this stop codon, which occurs early in the gene, is occasionally read through during transcription.

Eight patients had new missense mutations. Three of these resulted in a mild phenotype, these were: D45N, which substitutes one polar amino acid for another although a charge is lost; N115Y, which changes an acidic amino acid to a basic one, but in an non-conserved region of the sulphatase family of enzymes; and E434K, which changes an acidic amino acid to a basic one. Two mutations that substitute the turn inducing amino acid proline $(\mathrm{P} 228 \mathrm{~L}$ and P266R) resulted in intermediate and severe phenotypes, respectively. Presumably, this is because both mutations are likely to affect the tertiary structure of the IDS protein. The P266R mutation was identified in two unrelated UK patients but no material was available from maternal grandmothers, so that it is not known whether the mutation was inherited from a common ancestor. The I485K mutation substitutes a basic amino acid for a branched chain amino acid and resulted in a severe phenotype. A different mutation (I485R) has already been identified in this $\operatorname{codon}^{11}$; this mutation also resulted in a severe phenotype. The W502C mutation substitutes a sulphur amino acid for a polar amino acid in a hydrophobic domain and probably affects the tertiary structure of the IDS protein. Thus, it is not surprising that it results in a severe phenotype.

Five patients had new mutations that affect splicing. Two of these mutations disrupt acceptor slice sites. IVS1-2 $\mathrm{a} \rightarrow \mathrm{g}$ destroys the essentially invariant $A G$ of the splice site (agAT $\rightarrow$ ggat), and would be expected to result in exon skipping and the creation of a premature stop codon in exon four. Hence, it is not surprising that this patient presented with a severe phenotype. IVS2-10 $\mathrm{t} \rightarrow \mathrm{g}$ substitutes a purine for a pyrimidine in the acceptor site consensus sequence. This substitution activates a cryptic splice site within exon 3 and results in premature termination. Because the patient has a mild phenotype, it is probable that the normal splice site is also used occasionally, producing sufficient normal enzyme protein to prevent central nervous system involvement. Three mutations affected donor splice sites. IVS $5+2 \mathrm{t} \rightarrow \mathrm{g}$ destroys the essentially invariant gt of the donor splice site (AGgt $\rightarrow$ AGGG). This creates a premature stop signal in intron 5, with probable truncation of the IDS protein and, as would be predicted, results in a severe phenotype. The L236L mutation does not change an amino acid but changes the last base of the final codon of exon 5 and, thus, disrupts the consensus sequence of the donor splice site $(\mathrm{AGgt} \rightarrow \mathrm{AAGT})$. Again, this would introduce a stop codon in intron 5, resulting in truncation of the IDS protein and producing the observed severe phenotype. The IVS $7+2 \mathrm{t} \rightarrow \mathrm{c}$ mutation again destroys the essentially invariant gt of the donor splice site (TGgt $\rightarrow$ TGGC), producing premature termination in intron 7 , and resulting in severe clinical features.

Six patients had new single base deletions; four of these, c500delA, c705delC, c1023delA, and c1049delA, produced a severe phenotype as would be expected for frame shift mutations that induce premature termination. A fifth, c1576delG, is close to the end of the IDS gene and changes only 22 amino acids, with truncation of the IDS protein by only two amino 
acids. It is not surprising that this patient has mild clinical features. More surprising is the c1141delC mutation. This frame shift mutation changes nine amino acids and then creates a TGA termination codon within exon 8 . This would be expected to truncate the IDS protein by 161 amino acids, yet the patient has a mild phenotype.

Three patients had new single base insertions. The c709G710ins mutation resulted in a severe phenotype, as would be expected for a frame shift mutation that produces premature termination. However, the c70T71ins and c653C654ins mutations were detected in patients with intermediate and mild phenotypes, respectively. This is difficult to explain in view of the apparent frame shift and termination that they produce. Several single base deletions have been reported previously and these have resulted in all three types of clinical presentation. ${ }^{3}$ This illustrates the difficulty of predicting clinical phenotypes from genotype information, particularly when only genomic sequence data is available. Representative illustrations of missense, nonsense, and splicing mutations are shown in fig 1 , as are single base insertions and deletions.

Four patients had complete deletions or rearrangements of the IDS gene. Two of these have been reported previously, ${ }^{13}$ and were identified by Southern blotting using a full length cDNA probe. ${ }^{4}$ Two more patients with apparent full gene deletions or rearrangements were identified by failure to amplify all nine exons of the IDS gene by PCR (data not shown). Interestingly, in one of these latter patients, the pseudogene sequence $^{14}$ seems to be intact because a PCR product was obtained for exon 3 alone when

Table 2 Mutations identified in MPS II patients

\begin{tabular}{|c|c|c|c|c|c|c|c|c|c|}
\hline Patient & Age & Mutation & $\begin{array}{l}\text { Exon/ } \\
\text { intron }\end{array}$ & Base change & $\begin{array}{l}c D N A \\
\text { position }\end{array}$ & Effect on protein & Phenotype & Population & Ref \\
\hline JS & $28 \mathrm{~A}$ & $\mathrm{R} 8 \mathrm{X}$ & I & $\mathrm{CGA} \rightarrow \mathrm{TGA}$ & 22 & Termination & Mild & UK & TS \\
\hline DT & $9 \mathrm{~A}$ & c70T71ins & I & $\mathrm{CTC} \rightarrow \mathrm{CTTC}$ & $70-71$ & FS changes 22 aa, termination in exon 2 & Intermediate & UK & TS \\
\hline $\mathrm{T} \mathrm{K}$ & $9 \mathrm{~A}$ & IVS1-2 a $\rightarrow \mathrm{g}$ & $\begin{array}{l}\text { Intron } \\
1\end{array}$ & $\mathrm{ag} \rightarrow \mathrm{gg}$ & & Destruction of 3' splice site, exon skipping & Severe & Sweden & TS \\
\hline JW & $4 \mathrm{~A}$ & $\mathrm{D} 45 \mathrm{~N}$ & II & $\mathrm{GAT} \rightarrow \mathrm{AAT}$ & 133 & $\begin{array}{l}\text { Charged polar aa to uncharged polar aa in a position } \\
\text { conserved in seven sulphatases }\end{array}$ & Mild & UK & TS \\
\hline MW & $10 \mathrm{~A}$ & Q80X & II & $\mathrm{CAG} \rightarrow \mathrm{TAG}$ & 238 & Termination & Severe & UK & 5 \\
\hline $\mathrm{DN}$ & $10 \mathrm{~A}$ & IVS2-10 t $\rightarrow \mathrm{g}$ & $\begin{array}{l}\text { Intron } \\
3\end{array}$ & $\mathrm{gctc} \rightarrow \mathrm{gcgc}$ & - & $\begin{array}{l}\text { Alternate splicing in exon } 3 \text {, loss of } 14 \text { aa, } 2 \text { changed aa, } \\
\text { then termination }\end{array}$ & Mild & UK & TS \\
\hline SH & $9 \mathrm{~A}$ & $\mathrm{C} 84 \mathrm{X}$ & III & $\mathrm{TGC} \rightarrow \mathrm{TGA}$ & 252 & Termination & Severe & UK & TS \\
\hline RL & $16 \mathrm{D}$ & $\mathrm{C} 84 \mathrm{X}$ & III & $\mathrm{TGC} \rightarrow \mathrm{TGA}$ & 252 & Termination & Severe & UK & TS \\
\hline BB & $13 \mathrm{~A}$ & P86L & III & $\mathrm{CCG} \rightarrow \mathrm{CTG}$ & 257 & $\begin{array}{l}\text { Changes proline, probable effect on tertiary structure of } \\
\text { protein }\end{array}$ & Severe & UK & 6 \\
\hline TJP & $8 \mathrm{~A}$ & P86L & III & $\mathrm{CCG} \rightarrow \mathrm{CTG}$ & 257 & $\begin{array}{l}\text { Changes proline, probable effect on tertiary structure of } \\
\text { protein }\end{array}$ & Severe & $\begin{array}{l}\text { South } \\
\text { Africa }\end{array}$ & 6 \\
\hline $\mathrm{CC}$ & $1 \mathrm{~A}$ & P86L & III & $\mathrm{CCG} \rightarrow \mathrm{CTG}$ & 257 & $\begin{array}{l}\text { Changes proline, probable effect on tertiary structure of } \\
\text { protein }\end{array}$ & Unknown & Ireland & 6 \\
\hline GP & $26 \mathrm{~A}$ & N115Y & III & $\mathrm{AAC} \rightarrow \mathrm{TAC}$ & 343 & $\begin{array}{l}\text { Acidic to basic aa, in a position not conserved between } \\
\text { sulphatases }\end{array}$ & Mild & UK & TS \\
\hline SWS & ? & c500delA & IV & $\mathrm{AAC} \rightarrow \mathrm{A} \_\mathrm{C}$ & 500 & Changes 45 aa then termination & Severe & Taiwan & TS \\
\hline ID & $15 \mathrm{D}$ & $\mathrm{R} 172 \mathrm{X}$ & $\mathrm{V}$ & $\mathrm{CGA} \rightarrow \mathrm{TGA}$ & 514 & Termination & Severe & UK & 7 \\
\hline DD & $23 \mathrm{~A}$ & c653C654ins & $\mathrm{V}$ & $\mathrm{CCT} \rightarrow \mathrm{CCCT}$ & $653-654$ & FS, changes 9 aa, then termination & Mild & UK & TS \\
\hline DC & $11 \mathrm{~A}$ & P228L & $\mathrm{V}$ & $\mathrm{CCA} \rightarrow \mathrm{CTA}$ & 685 & $\begin{array}{l}\text { Changes proline, probable effect on tertiary structure of } \\
\text { protein }\end{array}$ & Intermediate & $\mathrm{UK}$ & TS \\
\hline $\mathrm{AO}$ & $6 \mathrm{D}$ & c705delC & $\mathrm{V}$ & $\mathrm{CCC} \rightarrow \mathrm{CC}_{-}$ & 705 & FS, changes 48 aa then termination & Severe & UK & TS \\
\hline MT & $10 \mathrm{~A}$ & IVS5 $+2 \mathrm{t} \rightarrow \mathrm{g}$ & $\begin{array}{l}\text { Intron } \\
5\end{array}$ & Aggt $\rightarrow$ AGGG & & Loss of splice site introduces 12 new aa then termination & Severe & UK & TS \\
\hline $\mathrm{BL}$ & $6 \mathrm{~A}$ & c709G710 ins & VI & $\mathrm{GAA} \rightarrow \mathrm{GGAA}$ & $709-710$ & FS, changes 20 aa then termination & Severe & UK & TS \\
\hline $\mathrm{CR}$ & $13 \mathrm{~A}$ & L236L & $\mathrm{V}$ & Aggt-AAGT & $708 ? ?$ & Loss of splice site introduces 12 new aa then termination & Severe & UK & TS \\
\hline CWJ & ? & E245X & VI & $\mathrm{GAG} \rightarrow \mathrm{TAG}$ & 733 & Termination & Severe & Korea & TS \\
\hline PR & $3 \mathrm{D}$ & P266R & VI & $\mathrm{CCC} \rightarrow \mathrm{CGC}$ & 797 & $\begin{array}{l}\text { Changes proline, probable effect on tertiary structure of } \\
\text { protein }\end{array}$ & Severe & UK & TS \\
\hline DT & $15 \mathrm{D}$ & P266R & VI & $\mathrm{CCC} \rightarrow \mathrm{CGC}$ & 797 & $\begin{array}{l}\text { Changes proline, probable effect on tertiary structure of } \\
\text { protein }\end{array}$ & Severe & UK & TS \\
\hline OD & $3 \mathrm{~A}$ & S333L & VII & $\mathrm{TCG} \rightarrow \mathrm{TTG}$ & 998 & $\begin{array}{l}\text { Changes an acidic to a nonpolar aa in a region conserved } \\
\text { between sulphatases }\end{array}$ & Severe & Norway & 7 \\
\hline FP & Fetus & S333L & VII & $\mathrm{TCG} \rightarrow \mathrm{TTG}$ & 998 & $\begin{array}{l}\text { Changes an acidic to a nonpolar aa in a region conserved } \\
\text { between sulphatases }\end{array}$ & Severe & India & 7 \\
\hline SM & $7 \mathrm{~A}$ & IVS7+2 $\mathrm{t} \rightarrow \mathrm{c}$ & $\begin{array}{l}\text { Intron } \\
7\end{array}$ & Tggt $\rightarrow$ TGGC & & Loss of splice site introduces 8 new aa then termination & Severe & UK & TS \\
\hline SD & $10 \mathrm{~A}$ & c1023delA & VIII & $\mathrm{GAA} \rightarrow \mathrm{GA}_{-}$ & 1023 & FS, changes 18 aa then termination & Severe & UK & TS \\
\hline CT & $14 \mathrm{D}$ & c1049delA & VIII & $\mathrm{AAT} \rightarrow \mathrm{A} \_\mathrm{T}$ & 1049 & FS, changes 9 aa then termination & Severe & UK & TS \\
\hline SSC & ? & G374G & VIII & $\mathrm{GGC} \rightarrow \mathrm{GGT}$ & 1122 & Creates alternate splice site with loss of 20 aa & Mild & Korea & 78 \\
\hline $\mathrm{AB}$ & $24 \mathrm{~A}$ & c1141delC & VIII & $\mathrm{CCT} \rightarrow \mathrm{C} \_\mathrm{T}$ & 1141 & FS, alters 9 aa then termination & Mild & UK & TS \\
\hline JC & $21 \mathrm{~A}$ & $\mathrm{E} 436 \mathrm{~K}$ & IX & $\mathrm{GAA} \rightarrow \mathrm{AAA}$ & 1300 & Changes acidic to basic aa in an area unique to IDS & Mild & UK & TS \\
\hline TF & $12 \mathrm{D}$ & $\mathrm{R} 443 \mathrm{X}$ & IX & $\mathrm{CGA} \rightarrow \mathrm{TGA}$ & 1327 & Termination & Intermediate & UK & 78 \\
\hline $\mathrm{UM}^{\star}$ & $16 \mathrm{~A}$ & $\mathrm{R} 443 \mathrm{X}$ & IX & $\mathrm{CGA} \rightarrow \mathrm{TGA}$ & 1327 & Termination & Intermediate & Asia & 9 \\
\hline BC & $3 \mathrm{~A}$ & Y466X & IX & $\mathrm{TAT} \rightarrow \mathrm{TAA}$ & 1398 & Termination & Severe & UK & TS \\
\hline MA & $8 \mathrm{~A}$ & R468Q & IX & $\mathrm{CGG} \rightarrow \mathrm{CAG}$ & 1403 & Changes a neutral to basic aa & Severe & UK & 10 \\
\hline DS & $6 \mathrm{~A}$ & R468Q & IX & $\mathrm{CGG} \rightarrow \mathrm{CAG}$ & 1403 & Changes a neutral to basic aa & Severe & UK & 10 \\
\hline NM & $10 \mathrm{D}$ & R468Q & IX & $\mathrm{CGG} \rightarrow \mathrm{CAG}$ & 1403 & Changes a neutral to basic aa & Severe & UK & 10 \\
\hline OS & $6 \mathrm{~A}$ & R468Q & IX & $\mathrm{CGG} \rightarrow \mathrm{CAG}$ & 1403 & Changes a neutral to basic aa & Severe & Sweden & 10 \\
\hline DCT & ? & $\mathrm{I} 485 \mathrm{R}$ & IX & ATA $\rightarrow$ AGA & 1454 & Changes nonpolar aa to basic polar aa & Severe & Taiwan & 11 \\
\hline II & $15 \mathrm{D}$ & $\mathrm{I} 485 \mathrm{~K}$ & IX & $\mathrm{ATA} \rightarrow \mathrm{AAA}$ & 1454 & Changes nonpolar aa to basic aa & Severe & UK & TS \\
\hline $\mathrm{AB}$ & $3 \mathrm{~A}$ & c1482-1488del & IX & CATAGACdel & 1 1482-1488 & FS, loss of 2 aa, 15 aa changed then termination & Unknown & UK & TS \\
\hline $\mathrm{JH}$ & $12 \mathrm{~A}$ & W502C & IX & $\mathrm{TGG} \rightarrow \mathrm{TGT}$ & 1506 & Changes a non polar to a polar sulphur aa & Severe & UK & TS \\
\hline EN & $18 \mathrm{~A}$ & c1576delG & IX & $\mathrm{TGG} \rightarrow \mathrm{TG}_{-}$ & 1575-1576 & FS, alters 22 aa then termination with loss of a further 2 aa & Mild & UK & TS \\
\hline
\end{tabular}

cDNA numbering follows the model proposed by Beutler et $a l^{12}$ beginning with the A of the initiation codon.

Age, present age in years or age at death (A, alive; D, dead).

*Female Hunter patient.

FS, Frame shift mutation; TS, this study. 

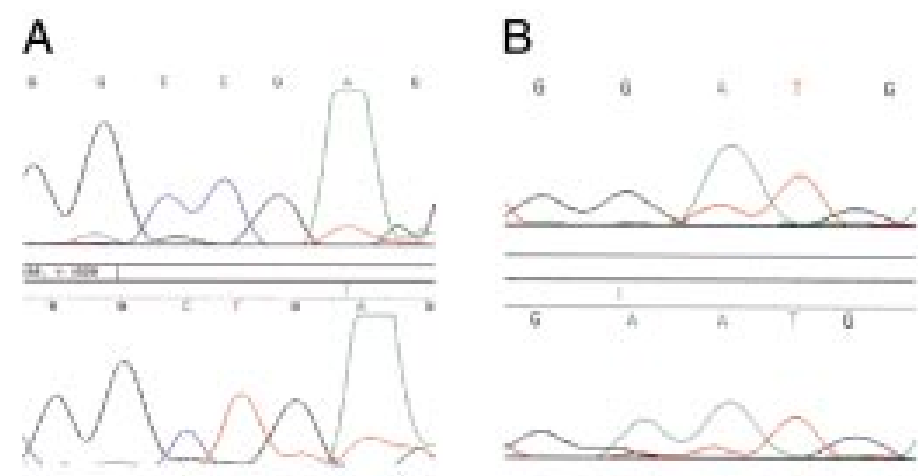

R8X CGA $\rightarrow$ TGA
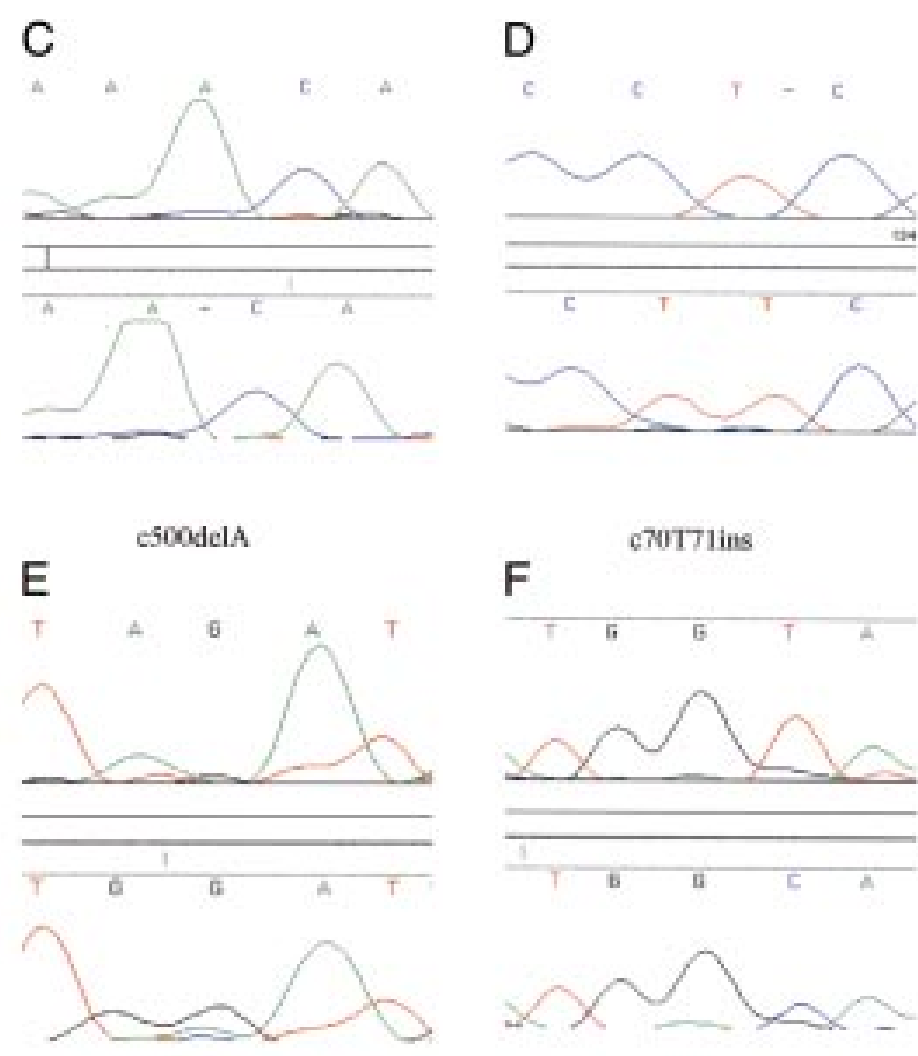

IVS1-2 a->g

IVS7+2 $1->\mathrm{C}$

Figure 1 Automated fluorescent dye terminator cycle sequencing of the IDS gene. In each case the upper electrophoretogram is the normal sequence and the lower one is the mutant sequence. (A) nonsense mutation R8X, (B) missense mutation D45N, (C) single base deletion c500delA, (D) single base insertion c70T71ins, (E) acceptor splice site mutation IVS1-2 $a \rightarrow g$, and $(F)$ donor splice site mutation IVS7 $+2 t \rightarrow c$.

using primers flanking this exon. Sequencing of this product revealed that the known $\mathrm{T} \rightarrow \mathrm{C}$ substitution that occurs naturally in the pseudogene sequence at position +12 was present alone, indicating that material from the IDS functional gene was not present (data not shown). Many previously described full gene deletions are thought to have occurred by recombination with the pseudogene. ${ }^{15}$ Our findings show that at least exon 3 of the pseudogene remains intact in this patient.

Table 3 Large deletions or rearrangements identified in MPS II patients

\begin{tabular}{|c|c|c|}
\hline Patient & Deletion & Reference \\
\hline RC & Complete IDS plus pseudogene & $\begin{array}{l}\text { Wraith et al } \\
1991^{13}\end{array}$ \\
\hline CS & Complete IDS plus pseudogene & $\begin{array}{l}\text { Wraith et al } \\
1991^{13}\end{array}$ \\
\hline $\mathrm{NH}$ & Complete IDS plus pseudogene & This study \\
\hline CS & $\begin{array}{l}\text { Complete IDS, pseudogene } \\
\text { sequence still intact }\end{array}$ & This study \\
\hline MW & Exons $1-6$ deleted & This study \\
\hline MH & Exon 4 deleted & This study \\
\hline
\end{tabular}

As would be expected, all four patients with full gene deletions had a severe clinical presentation, as did the two patients with one or more exons missing (table 3). A French MPS II patient has already been described with an exon 1 to 6 deletion similar to that seen in our patient. ${ }^{16}$

In general, patients with mutations that have been described previously (Q80X, ${ }^{9}$ P86L, ${ }^{10}$ $\mathrm{R} 172 \mathrm{X},{ }^{17} \mathrm{~S} 333 \mathrm{~L},{ }^{17} \mathrm{G} 374 \mathrm{G},{ }^{17}{ }^{18} \mathrm{R} 443 \mathrm{X},{ }^{17}{ }^{18}$ $\mathrm{R} 468 \mathrm{Q},{ }^{10}$ and $\mathrm{I} 485 \mathrm{R}^{11}$ ) showed identical phenotypes to those already reported. Interestingly, the Polish patient with the P86L mutation is reported to have an intermediate phenotype with normal psychomotor development. ${ }^{6}$ In contrast, two of our three patients with this mutation had the severe disease, with progressive mental retardation; the third patient was diagnosed at 4 months of age and, thus, it is too early to assess his degree of severity. Hence, there appears to be imperfect clinical correlation between patients with the same mutation. Public mutations are present in several geographically dispersed populations and apparently have arisen independently. For example, the P86L mutation was originally described in the Polish population. ${ }^{6}$ Our three patients with this mutation originated from the UK, South Africa, and Southern Ireland, and the mutation was not found in genomic DNA from two maternal grandmothers who were investigated, and was also not present in the mother of the third patient. This suggests that the three mutations have arisen recently and independently. This mutation has been described recently in a Japanese patient. ${ }^{17}$ Interestingly, reverse transcription PCR (RT-PCR) of mRNA produced two species of CDNA, one truncated by 44 base pairs. This was because the mutation activated the same cryptic splice site within exon 3 as the IVS2-10 t $\rightarrow \mathrm{g}$ mutation described in this report. We showed that this was also true for our patients with the P86L mutation (data not shown).

The most common mutation identified in this study was R468Q. This mutation has been reported in several other populations. ${ }^{10}{ }^{18-20}$ Indeed, this codon appears to be a "hot spot" for mutations because two other missense mutations have been described within it $\left(\mathrm{R} 468 \mathrm{~W}^{10}\right.$ and $\left.\mathrm{R} 468 \mathrm{~L}^{20}\right)$. However, most MPS II mutations appear to be private. Many also appear to have arisen recently, because most mutations were not found in the maternal grandmothers who we investigated, even though the mutation was present in their daughters with affected sons (table 4 ). This is 
Table 4 Identification of MPS II carriers among female family members

\begin{tabular}{lcc}
\hline Relative & Carriers & Not carriers \\
\hline Mothers & 27 & 4 \\
Sisters & 8 & 4 \\
Maternal grandmothers & 1 & 8 \\
Maternal aunts† & 0 & 22
\end{tabular}

* Sisters of 12 affected patients; tmaternal aunts of 13 affected patients.

corroborated by the absence of mutations in all 22 maternal aunts analysed. Nonetheless, mutation analysis is still of great value for identifying female carriers within a family. To date, 27 of 31 mothers and eight of 12 sisters have been shown to be carriers.

All new mutations identified either create stop codons, change charges, result in frame shifts, affect splicing, or produce gross gene deletions or rearrangements. Thus, it is probable that they are the disease causing mutations in these patients. However, investigation of mRNA and expression studies will be necessary to prove this conclusively.

Correlation between genotype and phenotype was uncertain using genomic DNA. Further investigations such as transcription or protein truncation tests are needed before the disease phenotype can be predicted with confidence.

1 Neufeld EF, Muenzer J. The mucopolysaccharidoses. In: Scriver CR, Beaudet AL, Sly WS, Valle D, eds. The metabolic and molecular basis of inherited disease, 7 th ed. New York: McGraw-Hill, 1995:2465-94

2 Lim TW, Leder IG, Bach G, Neufeld EF. An assay for iduronate sulphatase (Hunter corrective factor). Carbohydr Res 1974;37:103-9.

3 Hopwood JJ, Bunge S, Morris CP, et al. Molecular basis of mucopolysaccharidosis type II: mutations in the iduronate2-sulphatase gene. Hum Mutat 1993;2:435.-43.

4 Wilson PJ, Suthers GK, Callen DF, et al. Frequent deletions at Xq28 indicate genetic heterogeneity in Hunter syndrome. Hum Genet 1991;86:505-8.

5 Carrozzo R, Tonlorenzi R, Corsolini F, Gatti R. Two new nonsense mutations (Q80X and Q389X) in patients with severe Hunter syndrome. Hum Mutat 1996;7:184-5.
6 Popowska E, Rathmann M, Tylki-Szymansha A, et al. Mutations of the iduronate-2-sulphatase gene in 12 Polish patients with mucopolysaccharidosis II (Hunter syndrome). Hum Mutat 19995;5:97-100.

7 Flomen RH, Green PM, Bentley DR, Giannelli FG, Green EP. Detection of point mutations and a gross deletion in six Hunter syndrome patients. Genomics 1992;13:543-50.

8 Bunge S, Steglich C, Beck M, et al. Mutation analysis of iduronate-2-sulphatase gene in patients with mucopolysaccharidosis type II (Hunter syndrome). Hum Mol Genet 1992;1:335-9.

9 Broadhead DM, Kirk JM, Burt AJ, Gupta V, Ellis PM, Besley GTN. Full expression of Hunter's disease in a female with an X-chromosome deletion leading to non-random inactivation. Clin Genet 1986;30:392-8.

10 Whitley CB, Anderson RA, Aronovich EL, et al. Caveat to genotype-phenotype correlation in mucopolysaccharidosis II: discordant clinical severity of R468W and R468Q mutations of the iduronate-2-sulphatase gene. Hum Mutat 1993;2:235-7.

11 Shroder W, Wulff K, Wehnert M, Seidlitz G, Herrmann FH. Mutations of the iduronate-2-sulphatsae (IDS) gene in patients with Hunter syndrome (mucopolysaccharidosis II). Hum Mutat 1994;4:128-31.

12 Beutler E, McKusick VA, Motulsky AG, Scriver CR, Hutchinson F. Mutation nomenclature: nicknames, systematic names, and unique identifiers. Hum Mutat 1996;8: 203-6.

13 Wraith JE, Cooper A, Thornley M, Wilson PJ, Nelson PV, Morris CP, Hopwood JJ. The clinical phenotype of two patients with a complete deletion of the iduronate-2sulphatase gene (mucopolysaccharidosis II-Hunter syndrome). Hum Genet 1991;87:205-6.

14 Rathmann M, Bunge S, Steglich C, Schwinger E, Gal A. Evidence for an iduronate-sulphatase pseudogene near the functional Hunter syndrome gene in Xq27.3-q28. Hum Genet 1995;95:34-38.

15 Timms KM, Bonderson M, Ali Ansari-Lari M, et al. Molecular and phenotypic variation in patients with severe Hunter syndrome. Hum Mol Genet 1997;6:479-86.

16 Birot AM, Bouton O, Froissart R, Maire I, Bozon D. IDS gene-pseudogene exchange responsible for an intragenic deletion in a Hunter patient. Hum Mutat 1996;8:44-50.

17 Isogai K, Sukegawa K, Tomatsu S, et al. Mutation analysis in the iduronate-2-sulphatase gene in 43 Japanese patients with mucopolysaccharidosis type II (Hunter disease). $\mathcal{F}$ Inherit Metab Dis 1998;21:60-70.

18 Goldenfum SL, Young E, Michelakakis H, Tsagarakis S, Winchester B. Mutation analysis in 20 patients with Hunter disease. Hum Mutat 1996;7:76-8.

19 Rathmann M, Bunge S, Beck M, Kresse H, TylkiSzymanska A, Gal A. Mucopolysaccharidosis type II (Hunter syndrome): mutation "hot spots" in the iduronate2-sulphatase gene. Am f Hum Genet 1996;59:1202-9.

20 Sukagawa K, Tomatsu S, Fukao T, et al. Mucopolysaccharidosis type II (Hunter syndrome): identification of eight point mutations in the iduronate-2-sulphatase gene in Japanese patients. Hum Mutat 1995;6:136-43. 